\title{
sciendo
}

DOI 10.2478/sbe-2021-0050

SBE no. 16(3) 2021

\section{DIGITAL TRANSFORMATION AS STRATEGIC SHIFT - A BIBLIOMETRIC ANALYSIS}

\author{
OGREAN Claudia \\ Lucian Blaga University of Sibiu, Romania \\ HERCIU Mihaela \\ Lucian Blaga University of Sibiu, Romania
}

\begin{abstract}
:
The increasing interest for (the topic of) digital transformation - fueled by the synergies between technological developments (in terms of business-related applications of digital technologies) and businesses' search for (new determinants of digital technology-based) competitive advantage, while accelerated by the covid-19 pandemic - is an undeniable reality of nowadays (which is here to stay). Through a bibliometric analysis - built on data extracted from SCOPUS database and using VOSviewer - the paper aims to: make an overall assessment on the subject (and the ways it was addressed by academia); identify the main topics that configures the research on digital transformation (while being critical for the practice); assess the validity of digital transformation as strategic shift.
\end{abstract}

Key words: bibliometric analysis; digital transformation; strategic shift; vOSviewer

\section{Introduction}

At first sight, "digital transformation" may look like just any other buzz of nowadays' tech-geeks. Then again, when looking at some numbers, things get way more serious; a recent (March 19, 2021) post on Statista is portraying digital transformation not only as a real thing (translated into monetary terms), but also as a game changer for the global economy (that each and every actor must consider - in order to survive and thrive): "while in 2018, digitally transformed enterprises accounted for 13.5 trillion U.S. dollars of the global nominal GDP, in 2023 they are forecast to account for 53.3 trillion U.S. dollars, more than half of the overall nominal GDP. This signals that digital supremacy in the global economy is near" (Liu, S., 2021).

The covid-19 pandemic has given momentum to this already existing trend, making Twilio to conclude - based on a global survey (conducted in June 2020 and involving 2,569 respondents - directors or above) - that "covid-19 was the digital accelerant of the decade" (Twilio, 2020). This statement is supported by the following study results: $97 \%$ of the respondents reporting that COVID-19 has sped up digital transformation; $79 \%$ of them saying that COVID-19 increased their budget for digital 
transformation; and more than $70 \%$ of the companies - in various industries, from tech, energy and healthcare to construction and retail \& ecommerce - declaring that pandemic sped up their digital transformation a great deal (Twilio, 2020).

But what digital transformation is really about and why does it matter for organizations? Numerous extensive works / monographs have deepened these topics (especially during the last five years), emphasizing on the strategic, multivalent and complex character of digital transformation, as well as on its critical ripple effects (in both time and space) (Table 1). A common thread of these approaches is the strategic perspective they embrace, built on (and confirming, at the same time) the general assumption that digital transformation goes far beyond an organization's (digital) technologies and their use; it challenges the very existence of a business (not to mention its competitive advantage into an increasingly digital global economy), and therefore is asking for fundamental, strategic shifts (encompassing all the organization's areas and levels).

Table 1 Overall approaches on digital transformation - in monographs

\begin{tabular}{|c|c|}
\hline Rogers, 2016 & $\begin{array}{l}\text { "Digital transformation is not about technology - it is about strategy and new ways of } \\
\text { thinking. Transforming for the digital age requires your business to upgrade its } \\
\text { strategic mindset much more than its IT infrastructure." }\end{array}$ \\
\hline $\begin{array}{l}\text { Herbert, } \\
2017\end{array}$ & $\begin{array}{l}\text { "Real digital transformation isn't about getting your company to use a specific set of } \\
\text { new technology; it's about your company's ability to react and successfully utilize } \\
\text { new technologies and procedures - now and in the future." }\end{array}$ \\
\hline $\begin{array}{l}\text { Schallmo, \& } \\
\text { Daniel, } 2018\end{array}$ & $\begin{array}{l}\text { "The main objectives of digital transformation are obtaining new data and using this } \\
\text { data to reimagine (...) old, rule-based processes. There is a general consensus } \\
\text { among industry experts and professionals that digital transformation needs to be an } \\
\text { integrated and continuous part of any overall business strategy." }\end{array}$ \\
\hline Siebel, 2019 & $\begin{array}{l}\text { "Digital transformation is a disruptive evolution into an entirely new way of working } \\
\text { and thinking. And this process could require a full transformation of corporate body } \\
\text { parts for new ways of functioning". }\end{array}$ \\
\hline $\begin{array}{l}\text { Upadrista, } \\
2021\end{array}$ & $\begin{array}{l}\text { "Digital transformation is the transformation of business and organizational activities, } \\
\text { processes, competencies, and models to fully leverage the changes and } \\
\text { opportunities of a mix of digital technologies and their accelerating impact across } \\
\text { industries in a strategic and prioritized way, with present and future shifts in mind." }\end{array}$ \\
\hline
\end{tabular}

Within this framework, the paper's research questions are: How is academia addressing (via peer-reviewed literature) digital transformation in the "core economics" subject areas? What are the main granular topics that contribute to the literature? What is the relationship between the "hard" (technology-related) and the "soft" (strategy-related) side of digital transformation - as reflected in literature? By answering these questions, the paper aims to: make an overall assessment on the subject (and the ways it was addressed by academia); identify the main topics that configures the research (while being critical for the practice); asses the validity of digital transformation as strategic shift. 


\section{Methodology}

Usually, the bibliometric analysis performed in the fields of business and economics are using SCOPUS and/or Web of Science databases (Sánchez, Del Río, \& García, 2017; Gong, Xue, Zhao, Zolotova, Ji, \& Xu, 2019; Yas, Jusoh, Abbas, Mardani, \& Nor, 2020).

The current analysis is based on data extracted from SCOPUS - which was preferred over WoS due to its more "compact" approach in terms of subject areas considering the research topic. With only two (but specific and relevant) subject areas in "core economics" - Business, Management and Accounting and Economics, Econometrics and Finance - SCOPUS allows for more focused results on "digital transformation" (term that rather has a technical connotation). As the focus is on the impact of digital transformation on business and economics (as reflected by academia), the numerous WoS categories would have made the search less accurate.

So, a SCOPUS query was made - searching for "digital transformation" within Article title, Abstract, Keywords. Three filters were added: (1). publication year - all years to 2020 - to capture the dynamics of the researchers' interest and approaches related to the topic; (2). subject areas - limited to Business, Management and Accounting and Economics, Econometrics and Finance - to be able to investigate the "soft" (business and economics related) side and impact of digital transformation (not the pure technology related ones); and (3). Document type - Articles - to consider the most relevant (peerreviewed) published work in the field.

The query returned a total of 787 document results. A primary analysis of search results was firstly made (based on SCOPUS's Analyze search results tool) considering: documents by year, sources - publications, affiliations, authors, country/territory, subject areas, and funding sponsors. The further detailed bibliometric analysis was performed using VOSviewer, one of the common instruments when it comes to bibliometric analysis in business and economics (Rialti, Marzi, Ciappei, \& Busso, 2019; Verma, \& Gustafsson, 2020; Cavalcante, Coelho, \& Bairrada, 2021).

VOSviewer is "a software tool for creating maps based on network data and for visualizing and exploring these maps" (Van Eck, \& Waltman, 2021). Thus, the results provided by SCOPUS (including citation information, bibliographical information, abstract and keywords, and references) were exported (in CSV format) to become data sources for generating new maps. This allowed the analysis to be conducted by capitalizing on the maps created on both bibliographic and text data: bibliographic data were used to construct networks of co-occurrence of author keywords and citations (by sources, authors, and documents), while text data were used to construct the network of cooccurrence links between terms. When creating the maps, a Thesaurus file was used - for data cleaning (particularly by merging the different forms of the same term - singular and plural, American and British English, abbreviated and non-abbreviated).

The analysis of co-occurrence of Author keywords was preferred (over the cooccurrence of All keywords and Index keywords analysis) as Author keywords were considered to reflect better the authors' perspective on the researched topics. The map was built in VOSviewer setting a threshold of 5 occurrences of a keyword. Of the 2351 
keywords, 75 met the threshold; for each one of them, the total strength of the cooccurrence links with other keywords was calculated, the number of keywords selected remaining 75 .

The Citation - by Documents analysis was based on a threshold of 1 citation per document; it was met by 627 documents. For each one of them, VOSviewer calculated the number of citation links; the largest set of connected items led to 196 documents. The Citation - by Sources analysis set a minimum of 1 document per source and a minimum of 1 citation per source; 320 sources met the threshold. For each one of them, VOSviewer calculated the total strength of the citation links with other sources; the largest set of connected items led to 124 sources. The Citation - by Authors analysis considered a threshold of 1 document per author and 1 citation per author; it was met by 1652 authors. For each one of them, VOSviewer calculated the total strength of the citation links with other author; from the 100 selected authors, the largest set of connected items consisted of 93 authors.

Using text data (with terms extracted from the Title and Abstract files) a term cooccurrence map was then created - considering a minimum of 10 occurrences of a term; of the 15672 terms, 407 met the threshold. For each one of them VOSviewer calculated a relevance score and, by selecting the $60 \%$ most relevant items, the map consisting of 244 terms was made.

\section{Primary Analysis of Search Results}

The search for "digital transformation" on SCOPUS database - using the abovementioned filters - Articles published till the end of 2020, covering Business, Management and Accounting and Economics, Econometrics and Finance as Subject Areas - returned 787 documents between 2003 and 2020 (Fig. 1). More than three quarters of the articles $(75.47 \%$ ) have been published during the last two years of the analyzed timespan (2019-2020), suggesting a rapidly increasing interest on the topic in the foreseeable future - fueled by the synergies between technological developments (in terms of business-related applications of digital technologies) and businesses' search for (new determinants of digital technology-based) competitive advantage, while accelerated by the covid-19 pandemic.

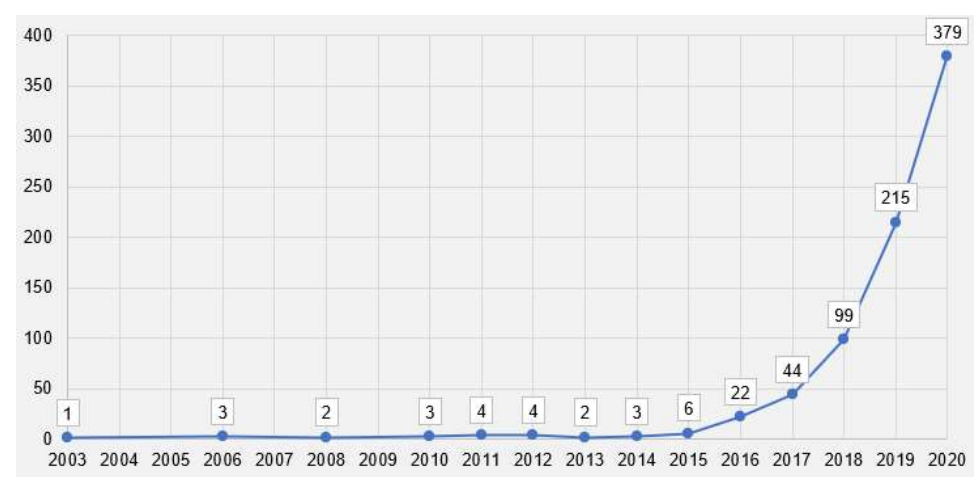

Figure 1. Documents by year (2003-2020)

Source: SCOPUS 
Out of 159 Sources (publications) in total, ZWF Zeitschrift Fuer Wirtschaftlichen Fabrikbetrieb is, by far, the journal with the highest number of articles mentioning "digital transformation": 26; the journal "provides expert articles on recent developments in production engineering as well as on industrial service processes. (It...) addresses companies' executives and specialists in research and development" (https://www.degruyter.com/journal/key/zwf/html). It is followed (Fig. 2) by MIS Quarterly Executive - having as mission "to encourage practice-based research in information systems and to disseminate the results of that research in a manner that makes its relevance and utility readily apparent" (https://aisel.aisnet.org/misqe/aimsandscope.html) with 14 articles, and Technological Forecasting and Social Change - "a major forum for those wishing to deal directly with the methodology and practice of technological forecasting and future studies as planning tools as they interrelate social, environmental and technological factors" (https://www.journals.elsevier.com/technological-forecastingand-social-change) - with 13 articles. Business Horizons and Business Process Management Journal complete the Top 5 sources - each one with 10 published articles addressing "digital transformation".

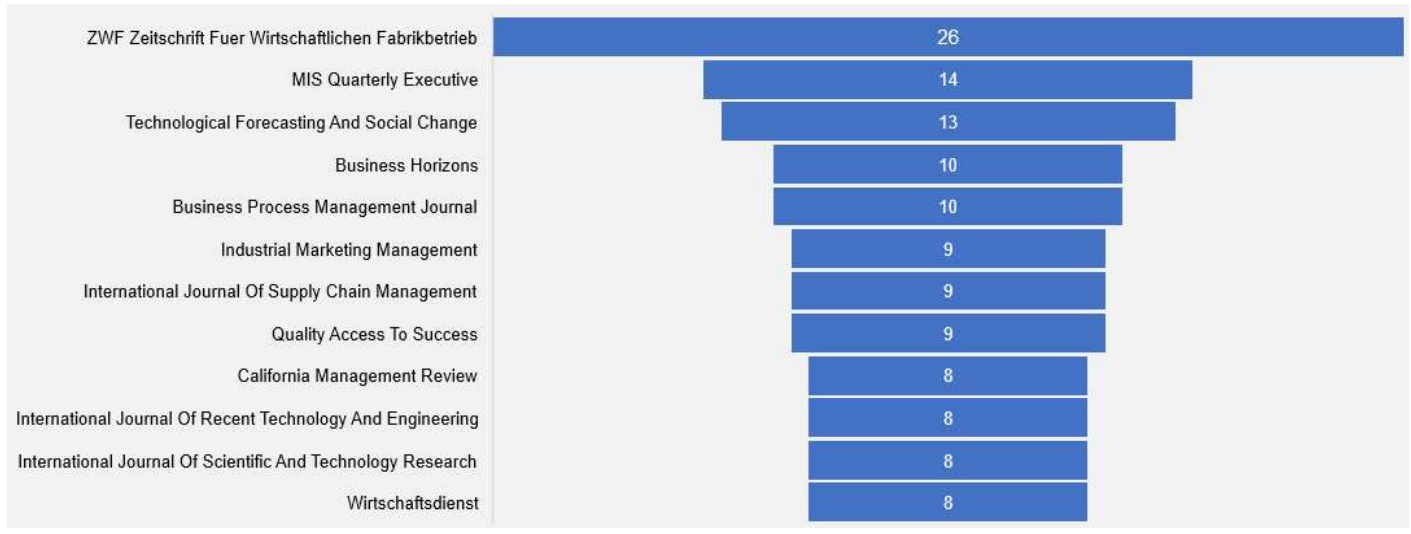

Figure 2. Top 10(-12) Sources - Publications

Source: SCOPUS

If considering Affiliation, 160 entities are represented; the highest number of articles (Fig. 3) has been published under the auspices of: Financial University under the Government of the Russian Federation (14 articles), Friedrich-Alexander-Universität Erlangen-Nürnberg and Ludwig-Maximilians-Universität München (11 articles each), Politecnico di Milano and Bina Nusantara University (10 articles each). 

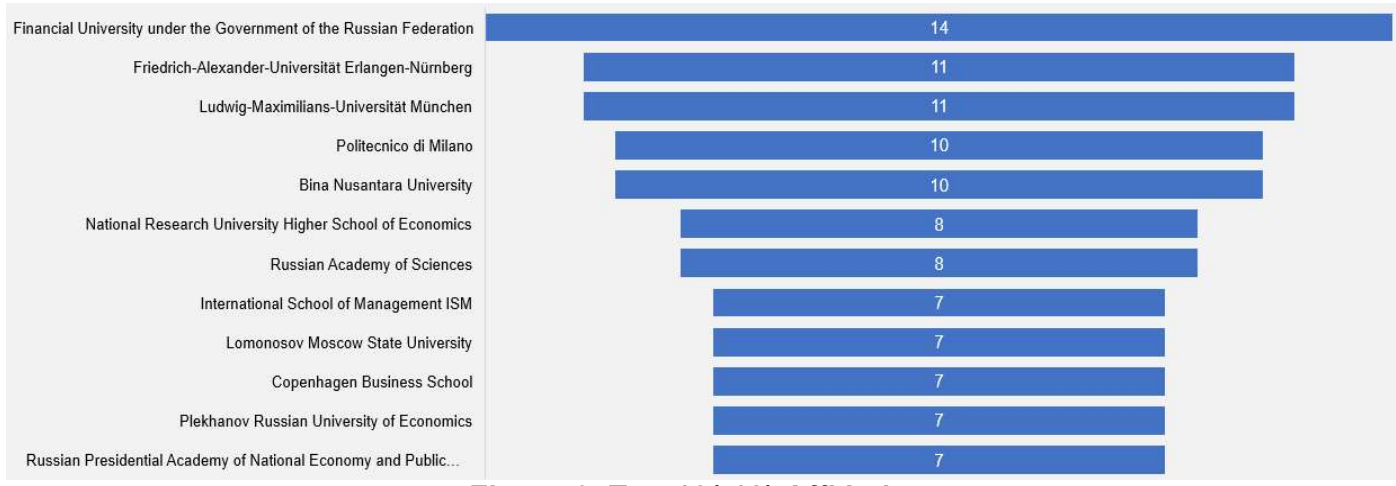

Figure 3. Top 10(-12) Affiliations

Source: SCOPUS

A total of 159 Authors have contributed to the 787 articles; Fig. 4 provides the top $10(-12)$ of them, in terms of number of published articles integrating "digital transformation". Two authors with German affiliation - Thomas Hess (affiliated to LudwigMaximilians-Universität München) and Ulrich Lichtenthaler (affiliated to the International School of Management, Koln) - each of them having published 8 articles on digital transformation - are followed here by two authors with Indonesian affiliation (Bina Nusantara University, Jakarta): Leonardus Wahyu Wasono Mihardjo (6 articles) and Sasmoko (5 articles).

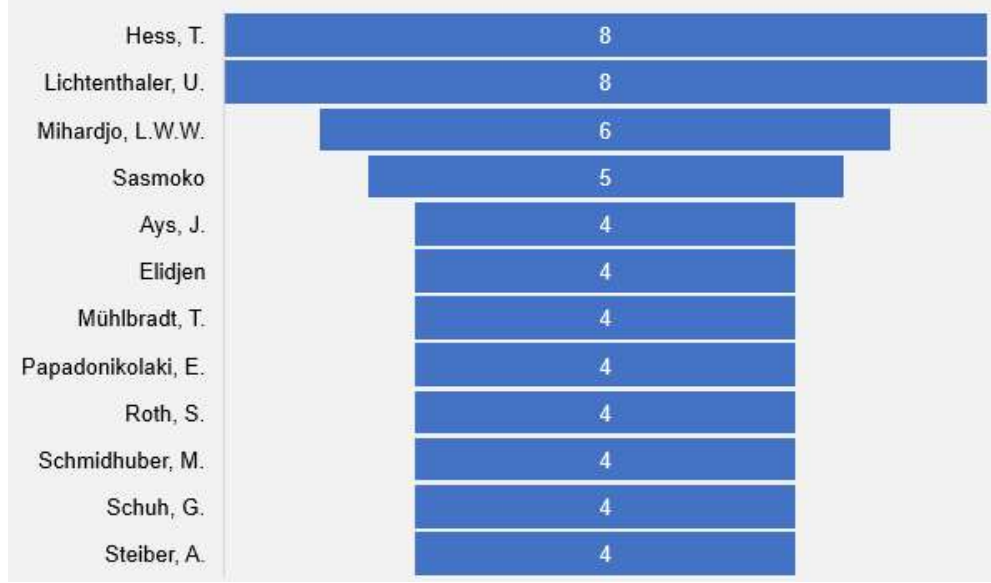

Figure 4. Top 10(-12) Authors

Source: SCOPUS

The Country/territory criterion reveals 75 different countries (the input is missing for 23 documents); the best represented countries are (Fig. 5): Germany (150 results), United States (100 results) and Russian Federation (90 results). 


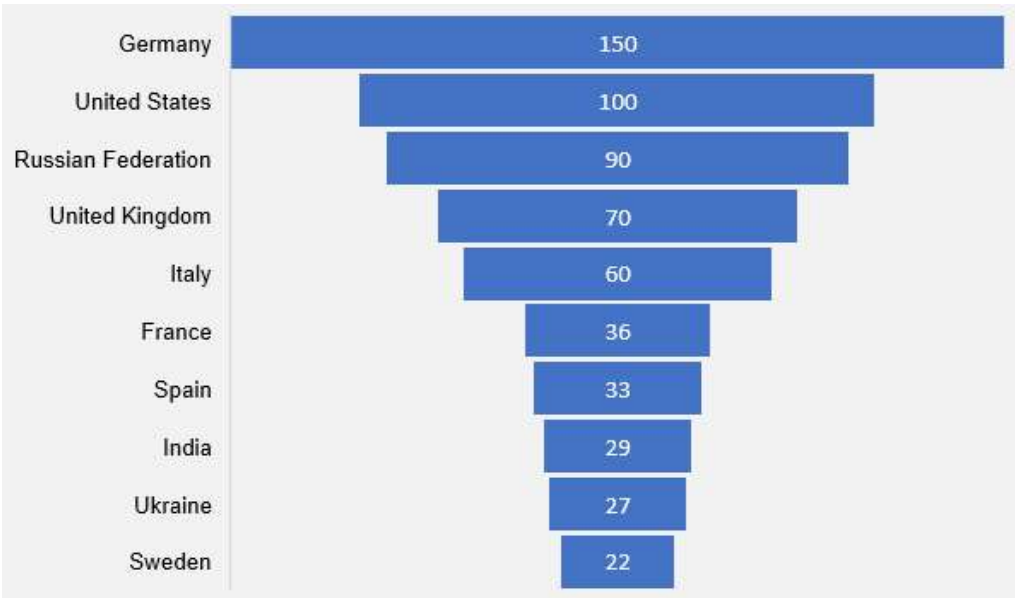

Figure 5. Top 10 Country/territory

Source: SCOPUS

The interdisciplinary nature of the topic has led to a total of nineteen Subject Areas covered by the resulted documents (Fig. 6). Besides Business, Management and Accounting and Economics (687 articles), and Econometrics and Finance (236 articles), the following Subject Areas register significant results in terms of number of articles: Social Sciences (182), Decision Sciences (172), Engineering (153), Computer Science (139), Psychology (25), and Environmental Science (23).
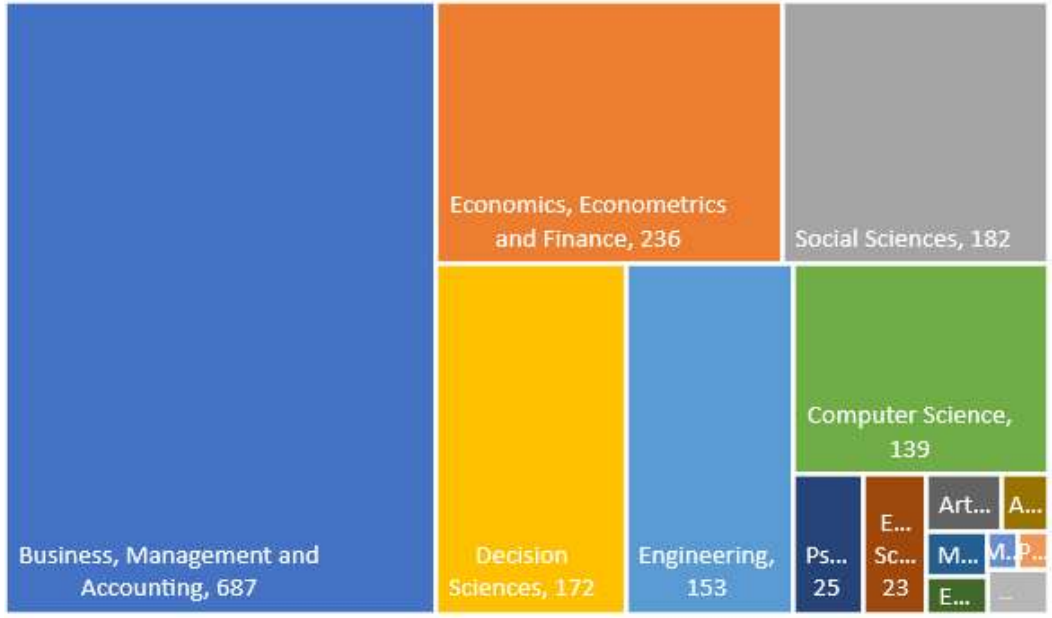

Figure 6. Subject Areas

Source: SCOPUS

Out of the 140 Funding Sponsors, the Russian Foundation for Basic Research is mentioned by 15 articles, the European Commission - by 9, while Coordenação de Aperfeiçoamento de Pessoal de Nível Superior and the European Regional Development Fund appear on 7 articles each (Fig 7). 


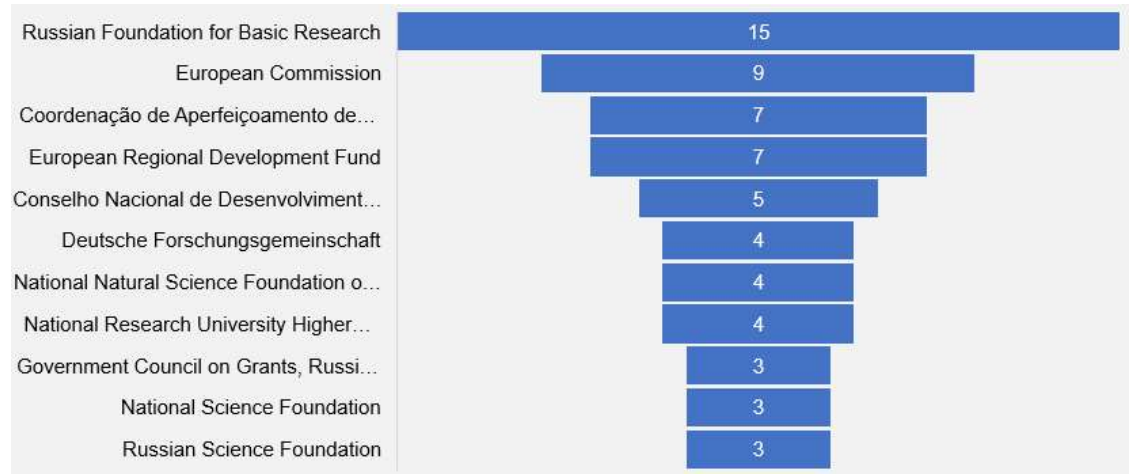

Figure 7. Top 10 Funding sponsors

Source: SCOPUS

\section{Bibliometric analysis using VOSviewer}

\section{Co-occurrence of author keywords}

Besides digital transformation (with 333 occurrences and 444 total link strength), the author keywords with the most powerful total link strength are: digitalization (169), industry 4.0 (104), innovation (89), digital technology (79), digital economy (70), artificial intelligence (66), big data (64), digitization (57), business model (50), and SME (47). Five clusters may be noticed (Fig. 8 and Table 2) to have emerged (considering a resolution of 1 , and a minimum cluster size of 10 items) around the following keywords: digitization (cluster 1 - red), digital economy (cluster 2 green), digitalization (cluster 3 - blue), artificial intelligence (cluster $4-$ yellow), and digital technology (cluster 5 - magenta).

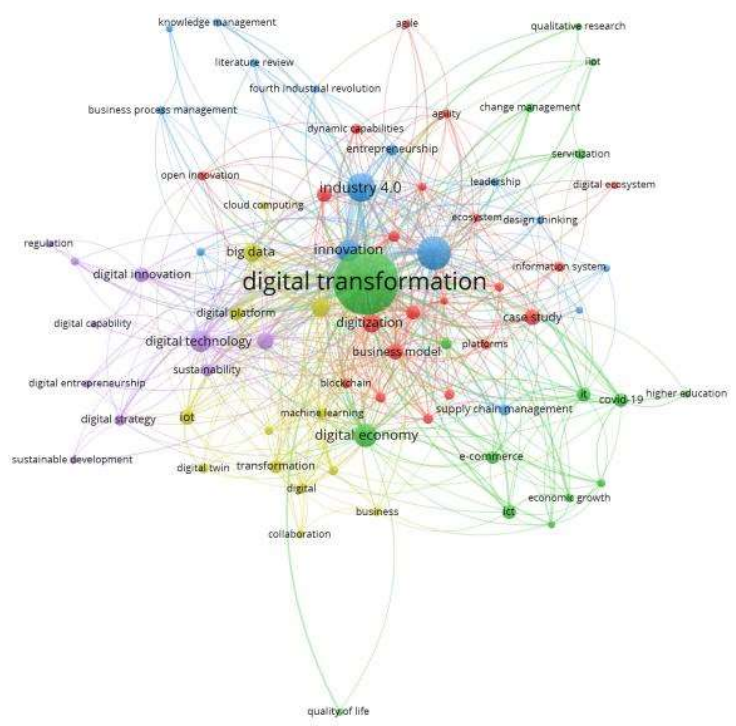

Figure 8. Co-occurrence of author keywords - map 


\section{Table 2 Co-occurrence of author keywords - clusters}

- Cluster 1 (red - 21 keywords): agile, agility, blockchain, business model, business model innovation, case study, customer experience, digital ecosystem, digitization, dynamic capabilities, ecosystem, fintech, information system, open innovation, platforms, service, strategy, supply chain, technology, value chain, value creation

- Cluster 2 (green - 16 keywords): change management, covid-19, digital economy, digital marketing, digital transformation, e-commerce, economic growth, global value chains, higher education, ict, iiot, it, pandemic, qualitative research, quality of life, servitization

- Cluster 3 (blue - 15 keywords): business process, business process management, design thinking, digital skills, digitalization, entrepreneurship, fourth industrial revolution, industry 4.0, innovation, knowledge management, leadership, literature review, organizational change, project management, supply chain management

- Cluster 4 (yellow - 13 keywords): ai, automation, big data, business, cloud computing, collaboration, digital, digital platform, digital transformation strategy, digital twin, iot, machine learning, transformation

- Cluster 5 (magenta - 10 keywords): digital capability, digital entrepreneurship, digital innovation, digital strategy, digital technology, healthcare, regulation, sme, sustainability, sustainable development

The analysis of the co-occurrence of author keywords map is favoring an overall assessment on the subject (and the ways it was addressed by academia): digitization is the first step of a complex process (with quite significant impacts) of digital transformation leading towards a digital economy - where digitalization, while making use of artificial intelligence (alongside automation, big data, cloud computing, digital twin, internet of things), is capitalizing on the digital technology.

\section{Citation - by Documents}

The most cited works (Fig. 9) focus on the following topics: Industry 4.0 technologies (Frank, Dalenogare, \& Ayala 2019) - about 500 citations; digital transformation strategy formulation (Hess, Benlian, Matt, \& Wiesböck, 2016) - around 400 citations; innovation diffusion in global contexts (Zhu, Dong, Xu, \& Kraemer, 2006) - over 350 citations. The other articles that complete the top 10 have, each one, more than 200 citations, and cover the following topics: (digital transformation-related) opportunities to create new business models (Berman, 2012); the digital transformation of innovation and entrepreneurship (Nambisan, Wright, \& Feldman, 2019); digital strategies for big old companies navigating digital transformation (Sebastian, Moloney, Ross, Fonstad, Beath, \& Mocker, 2017); digital innovation and transformation from an institutional perspective (Hinings, Gegenhuber, \& Greenwood, 2018); building dynamic capabilities for digital transformation (Warner, \& Wäger, 2019); designing for digital transformation (Majchrzak, Markus, \& Wareham, 2016); the role of dynamic capabilities in responding to digital disruption (Karimi, \& Walter, 2015).

Table 3 gathers the most cited documents - ranked by their respective links; all these documents have more than 10 links (while their rank may differ from the one given by citations). A quick look at these documents reveals the prevalence of a strategic perspective on (the different facets, dimensions, and forms of) digital transformation. 


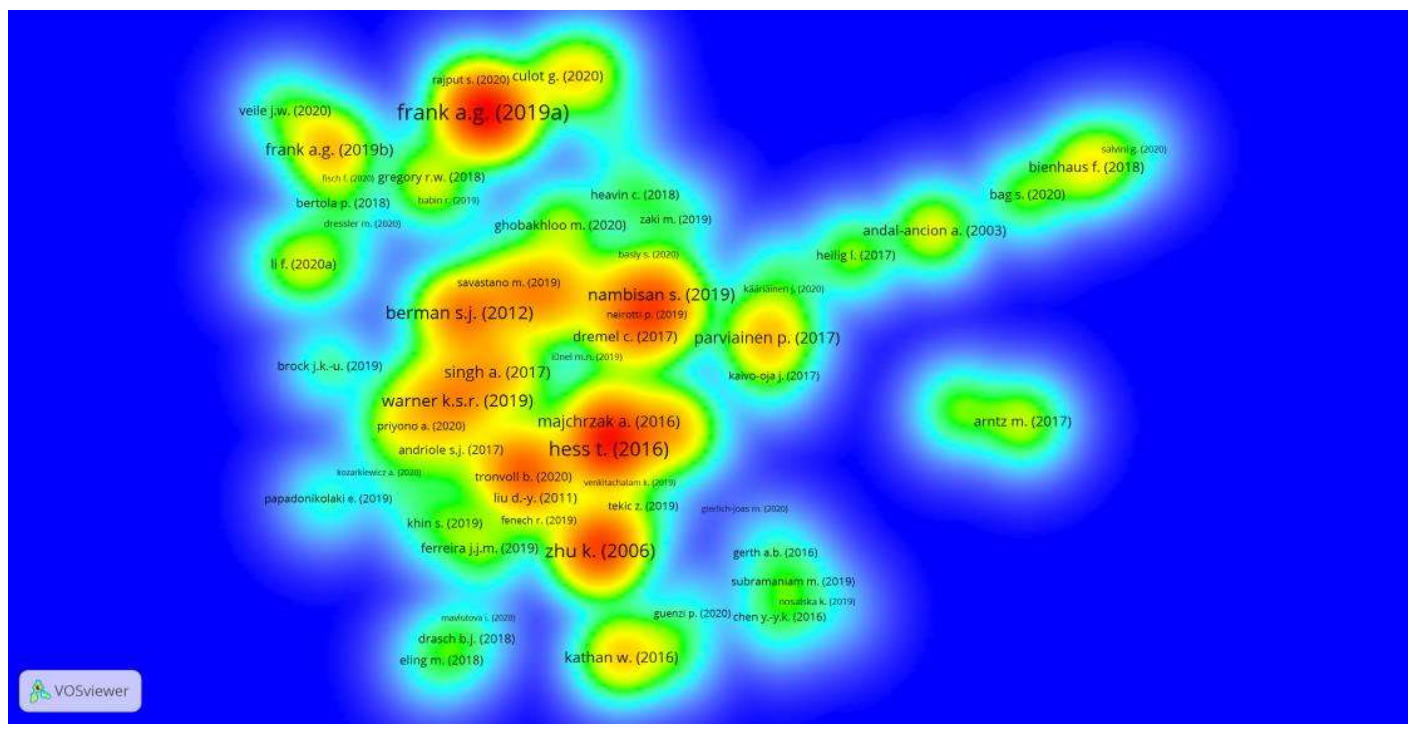

Figure 9. Citation map - by Documents (weights: citations)

Table 3 Citation - Top Documents (by links)

1. Hess, T., Benlian, A., Matt, C., \& Wiesböck, F. (2016). Options for formulating a digital transformation strategy. MIS Quarterly Executive, 15(2), 123-139.

2. Berman, S. J. (2012). Digital transformation: opportunities to create new business models. Strategy \& Leadership, 40(2), 16-24.

3. Warner, K. S., \& Wäger, M. (2019). Building dynamic capabilities for digital transformation: An ongoing process of strategic renewal. Long Range Planning, 52(3), 326-349.

4. Sebastian, I. M., Moloney, K. G., Ross, J. W., Fonstad, N. O., Beath, C., \& Mocker, M. (2017). How big old companies navigate digital transformation. MIS Quarterly Executive, 16(3), 197-213.

5. Singh, A., \& Hess, T. (2017). How chief digital officers promote the digital transformation of their companies. MIS Quarterly Executive, 16(1), 1-17.

6. Frank, A. G., Dalenogare, L. S., \& Ayala, N. F. (2019). Industry 4.0 technologies: Implementation patterns in manufacturing companies. International Journal of Production Economics, 210, 1526.

7. Sousa-Zomer, T. T., Neely, A., \& Martinez, V. (2020). Digital transforming capability and performance: a microfoundational perspective. International Journal of Operations \& Production Management, 40(07-aug), 1095-1128

8. Liu, D. Y., Chen, S. W., \& Chou, T. C. (2011). Resource fit in digital transformation: Lessons learned from the CBC Bank global e-banking project. Management Decision, 49(10), 1728-1742.

9. Hinings, B., Gegenhuber, T., \& Greenwood, R. (2018). Digital innovation and transformation: An institutional perspective. Information and Organization, 28(1), 52-61.

10. Karimi, J., \& Walter, Z. (2015). The role of dynamic capabilities in responding to digital disruption: A factor-based study of the newspaper industry. Journal of Management Information Systems, 32(1), 39-81.

11. Chanias, S., Myers, M. D., \& Hess, T. (2019). Digital transformation strategy making in predigital organizations: The case of a financial services provider. The Journal of Strategic Information Systems, 28(1), 17-33.

12. Loonam, J., Eaves, S., Kumar, V., \& Parry, G. (2018). Towards digital transformation: Lessons learned from traditional organizations. Strategic Change, 27(2), 101-109.

\section{Citation - by Sources}

The citation map gathering the 124 sources forming the largest set of connected items (Fig. 10) is complemented by the top 10 citation sources by total link strength (Table 4). MIS Quarterly Executive (with 14 documents) is, by far, the most cited publication when 
it comes to digital transformation (about 1300 citations - compared to less than 900 citations - corresponding to only 5 documents - registered by its follower publication International Journal of Production Economics). The same MIS Quarterly Executive journal takes the citation lead in terms of total link strength (88 - compared to the follower Strategy and Leadership journal - with a total link strength of 30 , due to only 2 documents).

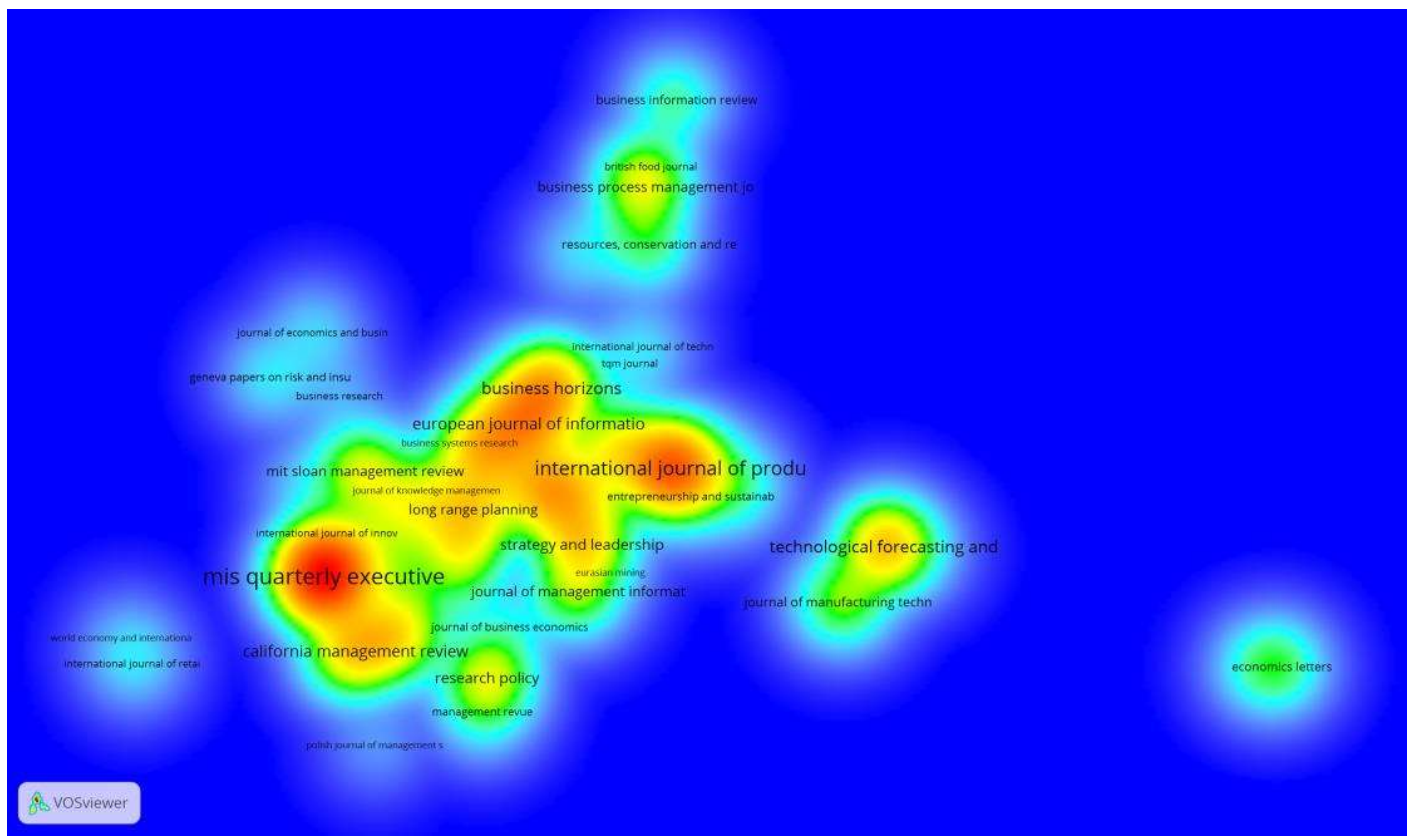

Figure 10. Citation map - by Sources (weights: citations)

Table 4 Citation - Top Sources (by total link strength)

\begin{tabular}{|ll|}
\hline 1. & MIS Quarterly Executive \\
2. & Strategy and Leadership \\
3. & Long Range Planning \\
4. & Management Decision \\
5. & Information and Management \\
6. & International Journal of Production Economics \\
7. & Journal of Strategic Information Systems \\
8. & Technological Forecasting and Social Change \\
9. & Business Horizons \\
10. & International Journal of Operations and Production Management
\end{tabular}

\section{Citation - by Authors}

Based on total citations (Fig. 11), the most cited authors (with about 700 citations each) are: Thomas Hess, Néstor F. Ayala, and Alejandro G.Frank. If considering the total link strength, the most cites authors are: Thomas Hess (8 documents, 747 citations, and 98 total link strength), Florian Wiesböck (3 documents, 441 citations, and 53 total link strength), Veronica Martinez, Andy N. Neely and Thayla T. Sousa-Zomer (1 document, 13 citations, and 40 total link strength). 


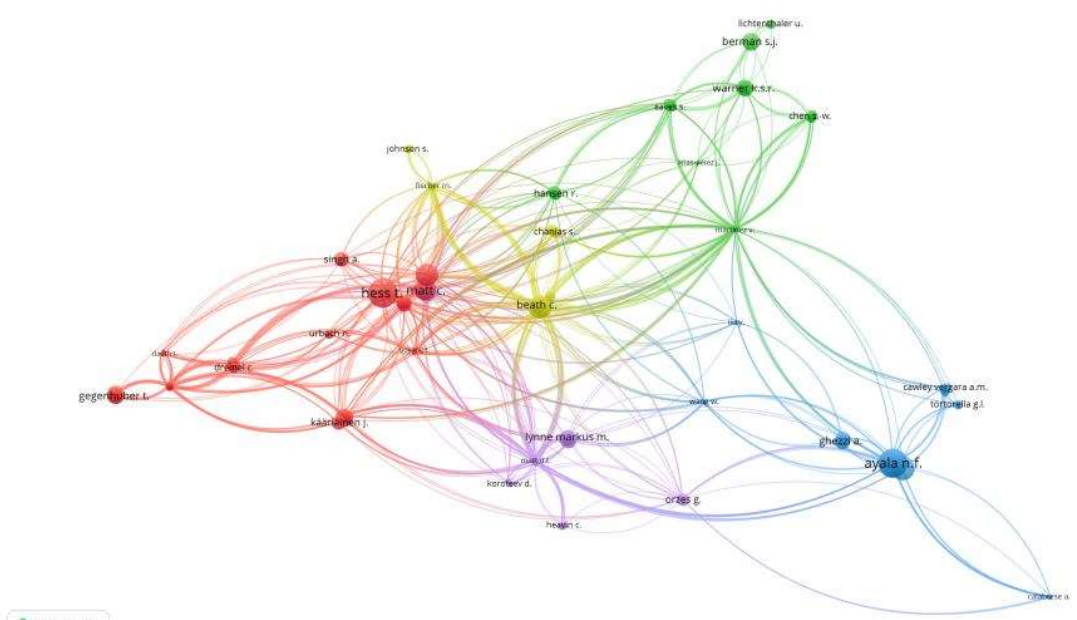

s. vosviever

Figure 11. Citation map - by Authors (weights: citations)

\section{Term co-occurrence map based on text data}

The term co-occurrence map based on text data (assuming a minimum cluster size of 10 items) reveals (Fig. 12) 4 clusters - emerged around the following keywords: economy, firm, internet, and customer. Fig. 13 emphasizes on the 4 keywords - as main granular topics configuring the literature on digital transformation) - and their networks, in order to capture: (a). the most significant items of each cluster and (b). the main items, outside each cluster, linked to the four keywords; thus, it provides a more comprehensive view on digital transformation (and its related topics/challenges) - as reflected in the business and economics literature.

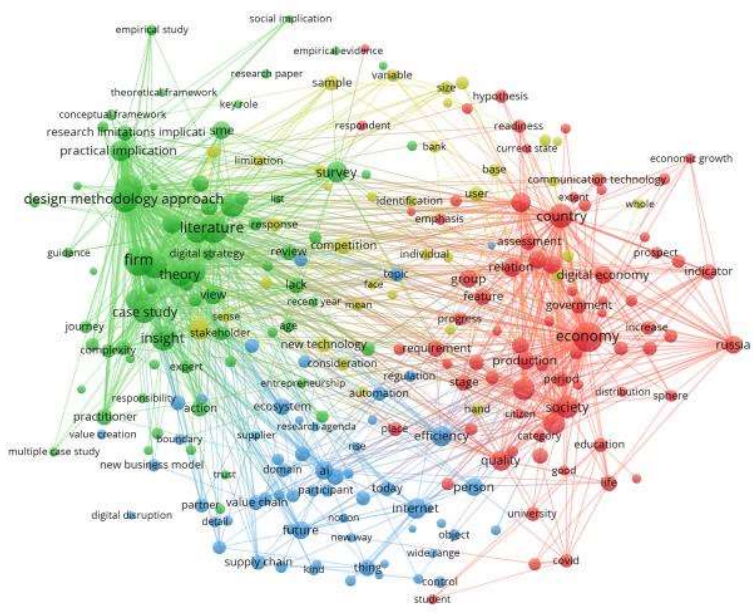

Figure 12. Term co-occurrence map based on text data 
Figure 13. Term co-occurrence map based on text data - details on clusters' keywords

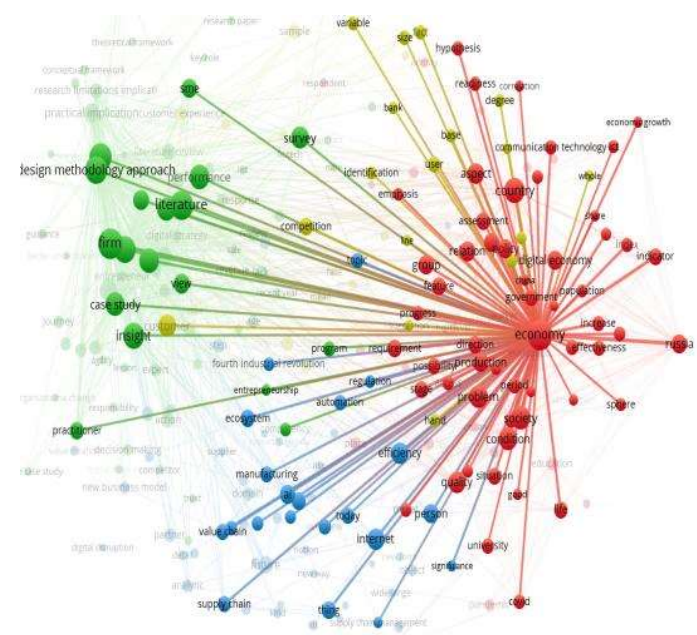

Cluster 1 - economy

Other relevant terms - citizen, city, communication technology, digital economy, economic growth, education, effectiveness, employment, government, ict, pandemic, productivity, quality, readiness, share, social medium, science, society

Related terms, outside the cluster - firm, capability, ecosystem, efficiency, internet, supply chain, performance, regulation

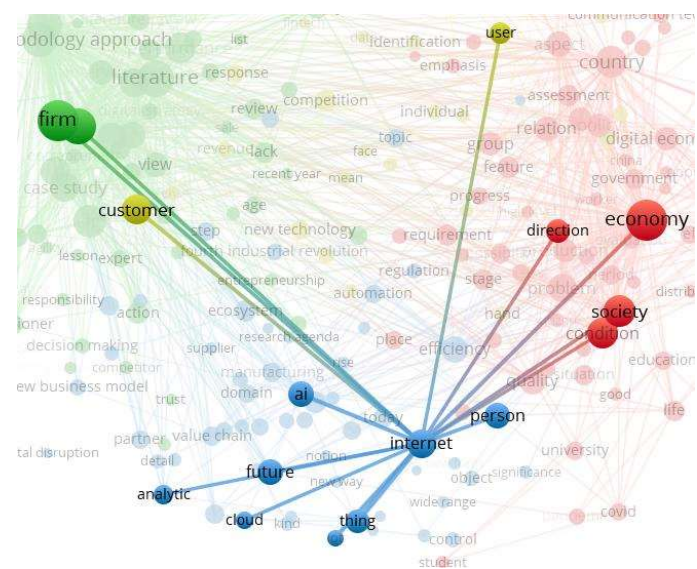

\section{Cluster 3 - internet}

Other relevant terms - ai, automation, cloud, collaboration, digital disruption, digital platform, digital twin, digital world, ecosystem, efficiency, fourth industrial revolution, healthcare, information system, iot, machine learning, manufacturing, new business model, supply chain management, sustainability, transparency, value creation

Related terms, outside the cluster - economy, society, customer, firm, capability, user

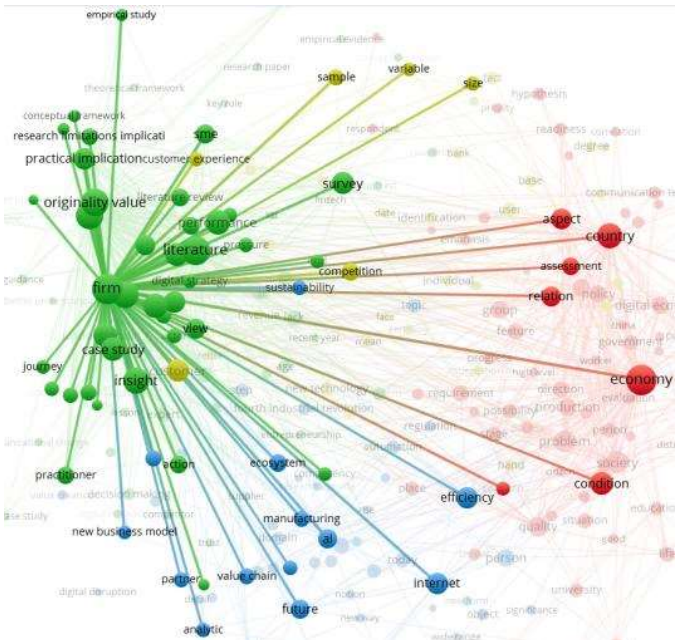

\section{Cluster - 2 firm}

Other relevant terms - agility, business model innovation, competitive advantage, complexity, decision making, digital innovation, digital transformation strategy, disruption, entrepreneurship, leader, performance, organizational change, responsibility, sme

Related terms, outside the cluster - ai, manufacturing, economy, internet, collaboration, competition, customer, new business model

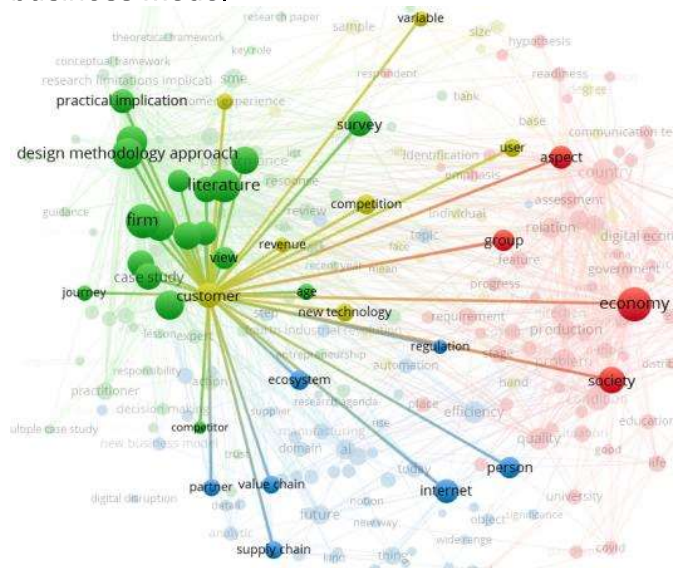

\section{Cluster 4 - customer}

Other relevant terms - bank, blockchain, competition, cooperation, customer experience, fintech, individual, new technology, perception, revenue, user

Related terms, outside the cluster - competitor, partner, value chain, supply chain, ecosystem, internet, person, group, journey, insight, regulation, society, economy, age, capability, success, performance, survey, manager 


\section{Discussion and Conclusions}

A closer look at the co-occurrence of author keywords map - whit an emphasis on digital transformation (Fig. 14) - confirms that digital transformation transcends the already "complicated" (for traditional businesses) fields of digital technologies and their (business-related) applications/solutions; moreover, it is not a topic to be addressed per se - because digital transformation is not an end, but a means - towards digital economy, economic growth, (better) quality of life, sustainable development, and sustainability.

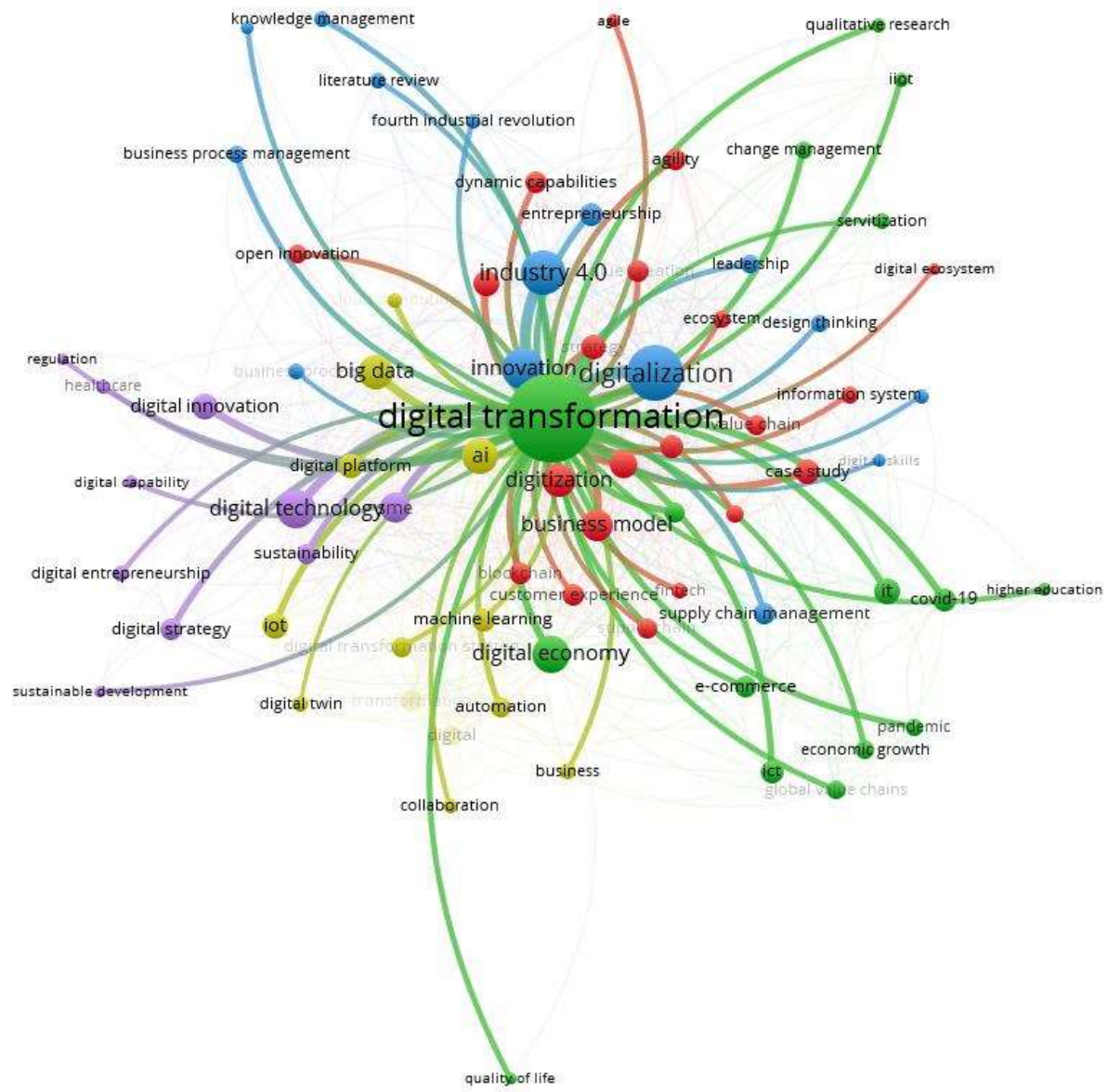

Figure 14. Co-occurrence of author keywords - emphasis on "digital transformation"

This idea is supported by the results of the citation analysis of top documents (Table 3): the strategic perspective on digital transformation characterizes not only the articles addressing the digital transformation strategy (Hess, Benlian, Matt, \& Wiesböck, 2016; Chanias, Myers, \& Hess, 2019), but also those discussing digital transformation in terms of: (a). antecedents/determinants - in reference to resource fit (Liu, Chen, \& Chou, 2011) or dynamic capabilities - in conjunction with strategic renewal (Warner, \& Wäger, 2019) or digital disruption (Karimi, \& Walter, 2015); (b). forms - as concerns the implementation patterns of industry 4.0 technologies in manufacturing companies (Frank, Dalenogare, \& Ayala, 2019), digital innovation and transformation (Hinings, Gegenhuber, \& 
Greenwood, 2018), the role of the chief digital officers in promoting the digital transformation (Singh, \& Hess, 2017), or the approach of old companies/traditional organizations (Sebastian, Moloney, Ross, Fonstad, Beath, \& Mocker, 2017; Loonam, Eaves, Kumar, \& Parry, 2018); (c). consequences/effects - by associating digital transforming capability with performance/competitive advantage (Sousa-Zomer, Neely, \& Martinez, 2020), or emphasizing on the opportunities for new business models (Berman, 2012).

Therefore, to be successful (both at organizational and societal levels), digital transformation requires a holistic approach at business level - based on a dedicated (digital transformation) strategy integrated into the core business strategy - accompanied by a "transformation" at management/leadership level - able to properly integrate the (industry and business specific) antecedents/determinants of the digital transformation, to optimally balance its forms, and to fully capitalize on its consequences/effects.

In conclusion, digital transformation implies a strategic shift: fundamental business and management challenges need to be overcome (in different organization-related areas - from digital skills or dynamic capabilities to change management or knowledge management), the business models need to be innovated, functional areas (from marketing to logistics and human resources) need to be reviewed, processes need to be either transformed (digitalized) or learned (e.g., design thinking, collaboration, or open innovation).

\section{References}

Berman, S. J. (2012). Digital transformation: opportunities to create new business models. Strategy \& Leadership, 40(2), 16-24.

Cavalcante, W. Q. D. F., Coelho, A., \& Bairrada, C. M. (2021). Sustainability and Tourism Marketing: A Bibliometric Analysis of Publications between 1997 and 2020 Using VOSviewer Software. Sustainability, 13(9), 4987.

Chanias, S., Myers, M. D., \& Hess, T. (2019). Digital transformation strategy making in pre-digital organizations: The case of a financial services provider. The Journal of Strategic Information Systems, 28(1), 17-33.

Frank, A. G., Dalenogare, L. S., \& Ayala, N. F. (2019). Industry 4.0 technologies: Implementation patterns in manufacturing companies. International Journal of Production Economics, 210, $15-26$.

Gong, R., Xue, J., Zhao, L., Zolotova, O., Ji, X., \& Xu, Y. (2019). A bibliometric analysis of green supply chain management based on the Web of Science (WOS) platform. Sustainability, 11(12), 3459.

Herbert, L. (2017). Digital transformation: Build your organization's future for the innovation age. Bloomsbury Publishing.

Hess, T., Benlian, A., Matt, C., \& Wiesböck, F. (2016). Options for formulating a digital transformation strategy. MIS Quarterly Executive, 15(2), 123-139.

Hinings, B., Gegenhuber, T., \& Greenwood, R. (2018). Digital innovation and transformation: An institutional perspective. Information and Organization, 28(1), 52-61.

Karimi, J., \& Walter, Z. (2015). The role of dynamic capabilities in responding to digital disruption: A factor-based study of the newspaper industry. Journal of Management Information Systems, 32(1), 39-81. 
Liu, D. Y., Chen, S. W., \& Chou, T. C. (2011). Resource fit in digital transformation: Lessons learned from the CBC Bank global e-banking project. Management Decision, 49(10), 1728-1742.

Liu, S. (2021). Nominal GDP driven by digitally transformed and other enterprises worldwide 20182023. https://www.statista.com/statistics/1134766/nominal-gdp-driven-by-digitallytransformed-enterprises/.

Loonam, J., Eaves, S., Kumar, V., \& Parry, G. (2018). Towards digital transformation: Lessons learned from traditional organizations. Strategic Change, 27(2), 101-109.

Majchrzak, A., Markus, M. L., \& Wareham, J. (2016). Designing for digital transformation: Lessons for information systems research from the study of ICT and societal challenges. MIS quarterly, 40(2), 267-277.

Nambisan, S., Wright, M., \& Feldman, M. (2019). The digital transformation of innovation and entrepreneurship: Progress, challenges and key themes. Research Policy, 48(8), 103773.

Rialti, R., Marzi, G., Ciappei, C., \& Busso, D. (2019). Big data and dynamic capabilities: a bibliometric analysis and systematic literature review. Management Decision. 57(8), 20522068

Rogers, D. (2016). The digital transformation playbook. Columbia University Press.

Sánchez, A. D., Del Río, M. D. L. C., \& García, J. Á. (2017). Bibliometric analysis of publications on wine tourism in the databases Scopus and WoS. European Research on Management and Business Economics, 23(1), 8-15.

Schallmo, A., \& Daniel, R. (2018). Digital Transformation Now! Guiding the Successful Digitalization of YourBusiness Model. Springer Science+ Business Media, LLC.

Sebastian, I. M., Moloney, K. G., Ross, J. W., Fonstad, N. O., Beath, C., \& Mocker, M. (2017). How big old companies navigate digital transformation. MIS Quarterly Executive, 16(3), 197-213.

Siebel, T. M. (2019). Digital transformation: survive and thrive in an era of mass extinction. RosettaBooks.

Singh, A., \& Hess, T. (2017). How chief digital officers promote the digital transformation of their companies. MIS Quarterly Executive, 16(1), 1-17.

Sousa-Zomer, T. T., Neely, A., \& Martinez, V. (2020). Digital transforming capability and performance: a microfoundational perspective. International Journal of Operations \& Production Management, 40(07-aug), 1095-1128

Upadrista, V. (2021). Formula 4. 0 for Digital Transformation: A Business-Driven Digital Transformation Framework for Industry 4. 0. Productivity Press.

Van Eck, N. J., \& Waltman, L. (2021). VOSviewer Manual (VOSviewer version 1.6.17), https://www.vosviewer.com/documentation/Manual Vosviewer 1.6.17.pdf

Verma, S., \& Gustafsson, A. (2020). Investigating the emerging COVID-19 research trends in the field of business and management: A bibliometric analysis approach. Journal of Business Research, 118, 253-261.

Warner, K. S., \& Wäger, M. (2019). Building dynamic capabilities for digital transformation: An ongoing process of strategic renewal. Long Range Planning, 52(3), 326-349.

Yas, H., Jusoh, A., Abbas, A. F., Mardani, A., \& Nor, K. M. (2020). A review and bibliometric analysis of service quality and customer satisfaction by using Scopus database. International Journal of Management (IJM), 11(8).

Zhu, K., Dong, S., Xu, S. X., \& Kraemer, K. L. (2006). Innovation diffusion in global contexts: determinants of post-adoption digital transformation of European companies. European journal of information systems, 15(6), 601-616.

*** Twilio, (2020). Covid-19 Digital Engagement Report. https://pages.twilio.com/rs/294-TKB-

300/images/UPDATE Aug Twilio COVID-19 Digital_Engagement Report.pdf 